\title{
Enhancing Collaborative Pharmaceutical Care for Patients with Chronic Kidney Disease: Survey of Community Pharmacists
}

\author{
Lisa Zhu, Andrea Fox, and Yu Chun Chan
}

\begin{abstract}
Background: The Kidney Care Clinic at Sunnybrook Health Sciences Centre provides multidisciplinary care for patients with stage 4 or 5 chronic kidney disease. These patients are at high risk of drug therapy problems. Clinic pharmacists review medications and provide recommendations at each visit, but potential gaps in care exist between clinic visits. Community pharmacists are ideally situated to identify and resolve drug therapy problems between visits.
\end{abstract}

Objectives: To determine community pharmacists' confidence in managing care for patients with chronic kidney disease; to identify opportunities for improving collaboration between clinic and community pharmacists; and to determine the key clinical information that community pharmacists would use when caring for these patients.

Methods: An anonymous survey was sent by mail and electronically to community pharmacies that were providing prescription medications for clinic patients. A total of 318 surveys were sent to 96 pharmacies. Data analysis was based on descriptive statistics, including frequencies, ranges, and measures of central tendency.

Results: Fifty-one completed surveys were returned (response rate 16\%). Thirty-five (69\%) of the responding pharmacists were not aware or were unsure that a patient from the Kidney Care Clinic was a client of their pharmacy. Forty-six (90\%) were confident in providing counselling about medications used to manage chronic kidney disease, and 32 (63\%) indicated confidence in recommending drug dosing changes based on kidney function. Forty-five (88\%) of the pharmacists indicated a willingness to play a greater role in reviewing medications for patients with chronic kidney disease, and all agreed that they would benefit from education about the complications of this disease and their management. Clinical information ranked most useful included an updated medication list with indications and details regarding recent medication changes.

Conclusions: Community pharmacists indicated willingness to have greater involvement in the care of patients with chronic kidney disease. The survey results revealed a need to increase awareness of clinic patients among community providers. Participants were receptive to continuing education, and initial efforts should focus on dosing adjustments of renal drugs and the complications of chronic kidney disease. Tools for transferring clinical information must be developed.

Keywords: seamless care, pharmaceutical care, chronic kidney disease, collaborative, clinic, community pharmacist

\begin{abstract}
RÉSUMÉ
Contexte : La clinique de santé rénale du Sunnybrook Health Sciences Centre fournit des soins multidisciplinaires aux patients atteints d'une insuffisance rénale chronique de stade 4 ou 5 . Ces patients sont exposés à un risque élevé de problèmes pharmacothérapeutiques. Les pharmaciens de la clinique effectuent une évaluation de la médication et formulent des recommandations à chaque visite, mais certaines lacunes potentielles dans les soins entre chaque visite à la clinique ne sont pas à exclure. Les pharmaciens communautaires sont les mieux placés pour déceler et résoudre les problèmes pharmacothérapeutiques entre les visites.
\end{abstract}

Objectifs : Déterminer à quel point les pharmaciens communautaires se sentent à l'aise à l'idée de prendre en charge les soins de patients atteints d'une insuffisance rénale chronique; identifier les occasions qui permettraient d'améliorer la collaboration entre les pharmaciens communautaires et ceux de la clinique; et préciser les informations cliniques clés que les pharmaciens communautaires pourraient utiliser lorsqu'ils s'occupent de ces patients.

Méthodes : Un sondage anonyme a été envoyé par la poste et par courriel aux pharmacies communautaires qui fournissent des médicaments d'ordonnance à des patients qui fréquentent la clinique. Un total de 318 sondages ont été envoyés à 96 pharmacies. L'analyse des données reposait sur des statistiques descriptives, notamment les fréquences, les étendues et les mesures de la tendance centrale.

Résultats : Cinquante et un sondages remplis ont été retournés (taux de réponse de $16 \%$ ). Trente-cinq (69\%) des pharmaciens ayant répondu au sondage ignoraient ou étaient incertains si un patient de la clinique de santé rénale était un client de leur pharmacie. Quarante-six (90\%) se sentaient à l'aise à l'idée de fournir des conseils sur les médicaments utilisés pour traiter l'insuffisance rénale chronique et 32 (63\%) ont reconnu qu'ils se sentaient à l'aise à l'idée de recommander des posologies adaptées à la fonction rénale. Quarante-cinq pharmaciens (88\%) ont manifesté leur volonté de jouer un rôle plus important dans l'évaluation de la médication des patients atteints d'une insuffisance rénale chronique et tous s'entendaient pour dire qu'ils tireraient profit d'une formation sur les complications de cette maladie et leur prise en charge. Parmi les informations cliniques jugées les plus utiles se trouvait une liste à jour des médicaments accompagnée de leurs indications et de précisions quant aux récents changements à la pharmacothérapie.

Conclusions : Les pharmaciens communautaires ont manifesté leur volonté de jouer un rôle plus important dans la prise en charge des patients atteints d'une insuffisance rénale chronique. Les résultats du sondage ont 
mis en relief la nécessité de mieux signaler les patients de la clinique aux pharmaciens communautaires. Les participants étaient ouverts à la formation continue et les mesures en ce sens devraient d'abord être axées sur l'ajustement posologique de médicaments éliminés par voie rénale et sur les complications liées à l'insuffisance rénale chronique. De plus, des outils visant à transmettre les informations cliniques doivent être développés.

Mots clés : soins continus, soins pharmaceutiques, insuffisance rénale chronique, collaboration, clinique, pharmacien communautaire

[Traduction par l'éditeur]

\section{NTRODUCTION}

$\mathrm{P}$ harmaceutical care is defined as the responsible provision of drug therapy for the purpose of achieving definite outcomes that improve a patient's quality of life. ${ }^{1}$ In the provision of pharmaceutical care, communication and collaboration are necessary for pharmacists in different practice settings to provide optimal and seamless care to patients.

Patients with chronic kidney disease (CKD) may be at higher risk of drug therapy problems (DTPs), as they often have multiple comorbidities, disease sequelae, and consequent polypharmacy. ${ }^{2-4} \mathrm{~A}$ study of patients with $\mathrm{CKD}$ attending a clinic in Quebec, Canada, revealed a mean of 5 to 6 comorbid conditions and an average of 10 to 13 prescribed medications. ${ }^{5}$ In addition, the patients were being followed by multiple prescribers. The diagnosis of CKD is frequently underrecognized, and patients with this condition are commonly seen by variably informed health providers. ${ }^{2,3}$ Failure to recognize CKD leaves patients at risk for inappropriate medication use that could accelerate disease progression. A prospective cohort study reported an overall 13\% risk of inappropriate medications, defined as exposure to contraindicated medications or medications requiring renal dosage adjustment, among communitydwelling elderly people with impaired kidney function. ${ }^{6}$ The risk of inappropriate medications was significantly higher among patients with more advanced renal dysfunction, occurring in nearly half of patients with estimated glomerular filtration rate (eGFR) between 30 and $59 \mathrm{~mL} \min ^{-1} 1.73 \mathrm{~m}^{-2}$ and in almost all patients with eGFR below $30 \mathrm{~mL} \mathrm{~min}^{-1} 1.73 \mathrm{~m}^{-2} .{ }^{6}$ In addition to prescription medications, over-the-counter and herbal products may also have deleterious effects on renal function or comorbid medical conditions. Laliberté and others ${ }^{5}$ found that, of 90 patients with moderate to severe $\mathrm{CKD}$, more than onethird were taking over-the-counter medications or natural products that were contraindicated or should be used with caution in CKD.

Community pharmacists are ideally situated to identify and perform follow-up on DTPs and to address medication needs, safety, and compliance. They may see patients more frequently than clinic pharmacists and could intervene at the point when a prescription is dispensed or a medication is purchased. Patient profiles in community pharmacies include medications dispensed over time and are linked with computerized programs to detect medication interactions. In addition, the MedsCheck program in Ontario, ${ }^{7}$ a government-funded, community pharmacy-based initiative, promotes one-on-one interviews between community pharmacists and patients to review medications, identify DTPs, and generate a best possible medication history (BPMH).

In light of the increased risk of DTPs in patients with CKD and the potential benefits of enhanced communication and collaboration between clinic pharmacists and community pharmacists, this research study had the following aims:

- to determine community pharmacists' level of confidence in managing patients with CKD

- to determine the feasibility of improving collaboration between clinic pharmacists and community pharmacists

- to determine what clinical information community pharmacists would utilize when caring for patients with $\mathrm{CKD}$

\section{METHODS}

The Kidney Care Clinic at Sunnybrook Health Sciences Centre, Toronto, Ontario, provides ambulatory care to patients with stage 4 to $5 \mathrm{CKD}\left(\mathrm{eGFR}<30 \mathrm{~mL} \mathrm{~min}^{-1} 1.73 \mathrm{~m}^{-2}\right)$ due to a variety of causes. Patients followed in clinic are seen by a multidisciplinary team that includes a nephrologist, a nurse practitioner, a dietician, a clinical pharmacist, and a social worker. During clinic visits, the clinical pharmacist reviews and updates patients' electronic medication records, provides recommendations to optimize medical therapy of CKD-related complications and comorbidities, provides patient education, and counsels patients on avoidance of nephrotoxic medications. However, the patients are usually seen in clinic only once every 2 to 3 months. Between clinic visits, patients may need ongoing monitoring for DTPs, they may be seen by other physicians who initiate or adjust medication therapy, and they may require advice on the use of over-the-counter or herbal products. 
This single copy is for your personal, non-commercial use only.

For permission to reprint multiple copies or to order presentation-ready copies for distribution, contact CJHP at cjhpedit@cshp.ca

\section{Study Participants}

At the time of the study, the Kidney Care Clinic had 167 patients. Community pharmacies where these patients had filled prescription medications as of June 2012 were identified through the electronic Sunnybrook outpatient nephrology database and the Ontario Drug Benefit drug profile viewer. A list of all community pharmacies within the Greater Toronto Area that had filled prescription medications for each patient was collected, and duplicates were removed to create the final list. Community pharmacies were contacted by telephone to determine the number of staff pharmacists working in each pharmacy. All full-time and part-time pharmacists were eligible to participate in the survey. Approval for the study was obtained from the Sunnybrook Health Sciences Centre Research Ethics Board.

\section{Survey}

Anonymous surveys were sent by regular mail to eligible community pharmacies. A web link to an online version of the survey was provided in the cover letter and on survey reminders faxed to the community pharmacies. The content of all sections of the survey was guided by literature related to the transfer of information between pharmacists in different practice settings. ${ }^{8-13}$ The survey consisted of 4 main sections to be completed by the community pharmacists: demographic characteristics, knowledge related to management of $\mathrm{CKD}$, attitudes toward increasing involvement in the care of patients with CKD, and clinical information needs.

\section{Data Analysis and Interpretation}

A convenience sample was used in this study, with the aim of surveying at least 200 community pharmacists. Survey data were analyzed with descriptive statistics, including frequencies, ranges, and measures of central tendency (mean, median, mode).

\section{RESULTS}

A total of 318 surveys were sent to pharmacists practising in 96 community pharmacies. Fifty-one completed surveys were received ( 42 by fax, 9 online), for a response rate of $16 \%$. Given the anonymous nature of the survey, data were not available on the number of different pharmacies represented by the returned surveys. Participants were, however, asked to indicate the type of primary practice site.

\section{Demographic Characteristics}

The average age of responding pharmacists was 41.8 years (standard deviation 11.1 years). Just over half of the respondents (26/50 [52\%]) were male, and about the same proportion (27/51 [53\%]) had been licensed before the year 2000. The largest
Table 1. Primary Practice Site and Employment Status of 51 Survey Respondents

Variable No. (\%) of Respondents

\section{Primary practice site}

Grocery or department store 4

Independent $18 \quad$ (35)

Chain, franchise $\quad 26 \quad$ (51)

Medical building, other 3 (6)

\begin{tabular}{lrr}
\hline Employment status & 12 & $(24)$ \\
Owner & 8 & $(16)$ \\
Manager & 25 & $(49)$ \\
Full-time & 6( & $12)$ \\
Part-time & \\
\hline
\end{tabular}

proportions of respondents worked for a chain or franchise and were employed in full-time positions (Table 1).

\section{Confidence Related to Managing CKD}

The majority of pharmacists were somewhat or very confident in counselling patients about medications used to manage $\mathrm{CKD}$ and the complications of CKD (Table 2). Thirty-two (63\%) of the respondents were confident in recommending medication adjustments based on kidney function, and the same proportion were confident in counselling patients about the complications of CKD. All respondents agreed or strongly agreed that they would benefit from continuing education on CKD complications and management.

\section{Attitude toward Involvement in Care of Patients with CKD}

Forty-five (88\%) of the pharmacists indicated a willingness to play a greater role in the review of medications for patients with chronic kidney disease. The majority of respondents agreed or strongly agreed that they would be willing to perform MedsCheck medication reviews for CKD patients and share these documented lists with clinic pharmacists (Table 3). However, 11 $(22 \%)$ of the pharmacists indicated that their current practice would not allow enough time to review patients' medications.

\section{Clinical Information Needs}

Thirty-five (69\%) of respondents were unaware or unsure that a Kidney Care Clinic patient was a client of their pharmacy. Respondents ranked an updated medication list from the clinic visit as the most useful type of clinical information (Box 1). They ranked name and contact information for the patient's clinic pharmacist as the type of information least likely to be used. For $33(67 \%)$ of 49 respondents, fax was the preferred method of information transfer, followed by email (9 [18\%]), a letter from the clinic pharmacist to be carried by the patient (5 [10\%]), and regular mail (2 [4\%]). Close to half (24 [47\%]) of all 51 respon- 
Table 2. Confidence Related to Managing Chronic Kidney Disease $(n=51)$

\begin{tabular}{|c|c|c|}
\hline Task & $\begin{array}{r}(\%) \text { of } \\
\text { Son } \\
\text { Very Con }\end{array}$ & $\begin{array}{l}\text { pondents } \\
\text { hat or } \\
\text { nt with Task }\end{array}$ \\
\hline $\begin{array}{l}\text { Counsel patient about medications to manage chronic kidney } \\
\text { disease and complications (e.g., ACE inhibitors, ARBs to } \\
\text { reduce proteinuria) }\end{array}$ & 46 & $(90)$ \\
\hline Identify medications that require renal dosage adjustmentq & 38 & $(74)$ \\
\hline Identify potentially nephrotoxic medications & 34 & $(67)$ \\
\hline $\begin{array}{l}\text { Recommend changes in drug dose or frequency on basis } \\
\text { of kidney function }\end{array}$ & 32 & (63) \\
\hline $\begin{array}{l}\text { Counsel patient about the complications of chronic kidney } \\
\text { disease (e.g., anemia, mineral bone disease) }\end{array}$ & 32 & (63) \\
\hline
\end{tabular}

\section{Table 3. Attitude toward Increasing Involvement in Care of Patients with Chronic Kidney Disease $(n=51)$}

\begin{tabular}{lcc} 
Aspect of Increased Involvement & $\begin{array}{c}\text { No. (\%) of Respondents } \\
\text { Who Agreed or } \\
\text { Strongly Agreed with } \\
\text { Increasing Involvement }\end{array}$ \\
\hline $\begin{array}{l}\text { Perform MedChecks medication reviews and share these } \\
\text { documented lists with clinic pharmacists. }\end{array}$ & 49 (96) \\
$\begin{array}{l}\text { Provide improved care if given patients' past medical } \\
\text { history/diagnoses }\end{array}$ & 46 & (90) \\
$\begin{array}{l}\text { Would like to play greater role in review of patients' medications } \\
\text { Would like to play greater role in identifying, monitoring, } \\
\text { and resolving drug therapy problems }\end{array}$ & 45 & $(88)$ \\
$\begin{array}{l}\text { Able to provide improved care if given current kidney function } \\
\text { (i.e., creatinine clearance) }\end{array}$ & 38 & (84) \\
\hline
\end{tabular}

dents indicated that their pharmacy did not have a process for storing and retrieving clinical patient information or they were unsure whether such a process existed.

\section{DISCUSSION}

The results of this study suggest that community pharmacists are interested in becoming more involved in the care of patients with CKD. However, they are hindered by a lack of essential clinical information and may not always be aware that a particular patient has CKD. These findings reveal a need to increase awareness of the identity of Kidney Care Clinic patients among local community pharmacies and to ensure that patients' community pharmacists are aware that they have CKD. Fink and others ${ }^{2}$ emphasized the need for innovative strategies for transmitting alerts about a patient's CKD to all health care providers, as a way to improve patient safety. Well-educated patients may be the most committed stakeholders in their own medical care. ${ }^{2}$ Initial steps in increasing provider awareness will involve encouraging clinic patients to inform all other health care providers of their kidney dysfunction.

It was surprising that respondents considered the name and contact information of the patient's clinic pharmacist as the clinical information least likely to be used. This finding empha-
Box 1. Top 5 Types of Clinical Information Ranked as Useful by Community Pharmacists

Updated medication list from clinic visit Name and contact information for the patient's clinic nephrologist Information about changes to medication therapy during clinic visits Current and past medical history and diagnoses

Purpose of medications that nephrologist prescribed for the patient

sizes the need to raise awareness among community pharmacists of the clinic pharmacist's role as an important liaison between the patient and patient's nephrologist.

Nearly all respondents indicated a willingness to perform medication reviews and share the results of such reviews with clinic pharmacists. This represents an opportunity for collaboration, with the potential of encouraging clinic patients to receive a MedsCheck medication review through their community pharmacy before each clinic visit. The BPMH prepared by the community pharmacy could then be shared with clinic pharmacists and could serve as a starting point for medication review during the clinic visit. Because of the potential time limitation reported by some community pharmacists, further work is required to determine the feasibility of this approach. In terms of clinical information needs, community pharmacists ranked an 
updated medication list from the patient's clinic visit as the most useful clinical information. To promote a 2 -way exchange of information, clinic pharmacists could share the updated BPMH with the patient's community pharmacy following each clinic visit. For example, the clinic administrative assistant could send the BPMHs to the community pharmacies by fax. Previous research within the hemodialysis setting has demonstrated the feasibility and benefits of such a process. In London, Ontario, a copy of patients' medication and allergy lists were faxed from a dialysis unit to community pharmacies. More than $80 \%$ of community pharmacists reported using this information to update patient files, and more than $90 \%$ considered the form an improvement in communication. ${ }^{11}$

The results of the current survey indicate that respondents are receptive to continuing education about $\mathrm{CKD}$ complications and their management. Initial efforts should focus on areas where respondents were least confident, including dosing adjustments for renal drugs and management of CKD complications. Previous research has suggested that education programs aimed at increasing pharmacists' competency in managing CKD increased the pharmacists' knowledge and ability to identify and intervene on DTPs. Matzke and others ${ }^{8}$ described the implementation of a 3-day pharmaceutical care preceptorship program in the nephrology setting. The program was designed for hospital pharmacists working with mostly outpatient nephrology patients in the United States. ${ }^{8}$ A survey of the participants showed increases in the number of pharmacist interventions and improvements in clinical indicators related to anemia and the management of renal bone disease. In Quebec, a training and communication-network program was designed to facilitate pharmaceutical care by community pharmacists. ${ }^{14}$ The 6-month pilot project included a 3-h workshop, links to patients' clinical information from CKD clinic visits, and access to a consultation service run by hospital nephrology pharmacists. Community pharmacists who participated in the program intervened more frequently for DTPs related to inappropriate dosage and inadequate medication use than their counterparts who did not participate. Laboratory test results were found to represent one of the most important sources of information for identifying DTPs, which demonstrates the value of increased access to clinical information. ${ }^{14}$

These programs were multifaceted, including live content delivery and integrating practical application and tools to ensure that pharmacists not only increased their knowledge but also were able to apply the knowledge to improve patient care. However, such programs are time- and resource-intensive. Prior research about community pharmacists' preferences related to continuing education has suggested that live lectures are preferred over written materials or videos for content delivery. ${ }^{15}$ Further work is required to explore the feasibility of developing and implementing a multifaceted educational program for the local community pharmacists whose patients are seen in the Kidney Care Clinic.

Of interest, these findings indicate a gap in the process of storing and retrieving clinical patient information within community pharmacies. Clinical patient information, if shared with community pharmacies, is useful only insofar as it can easily be stored and retrieved at the point of care. For patients with $\mathrm{CKD}$, the community pharmacy system would ideally be able to alert the pharmacist of potential nephrotoxic medications and flag prescriptions that might require dosing adjustment according to shared information about the patient's renal function. Additional details on the current processes and functions of different community pharmacy systems are needed.

\section{Limitations}

The study had several limitations. First, the sample size was small. In addition, the survey was voluntary, so the sample may have represented a relatively motivated group of community pharmacists, which might reduce the generalizability of the findings. The study gathered information on self-reported confidence in managing CKD patients and may not reflect the true competency of community pharmacists. It is reassuring, however, that this method of assessing community pharmacists' knowledge (self-reported competency) has been used in survey studies related to other chronic diseases. ${ }^{13,16,17}$ Despite these limitations, it is felt that the findings are informative and will be useful in gaining an understanding of gaps and opportunities for collaboration between clinic and community pharmacists. The results will also be useful in guiding the development of a process and tools for transferring clinical information. Future steps to expand on the results reported here could include gathering more detailed information from focus groups of community pharmacists.

\section{CONCLUSIONS}

Community pharmacists indicated willingness to have greater involvement in the care of patients with CKD. These results indicate a need for increased recognition of $\mathrm{CKD}$ among community providers, which should in turn improve patient safety. In addition, there is a need to increase awareness of the role of clinic pharmacists among community pharmacists, as a way to enhance collaboration. Community pharmacists were receptive to continuing education, and initial efforts should focus on dosing adjustments for renal drugs and management of CKD complications. Opportunities may exist for a 2-way exchange of patient information between clinic and community pharmacists, including BPMHs. Tools for transferring clinical information require further development.

\section{References}

1. Hepler CD, Strand LM. Opportunities and responsibilities in pharmaceutical care. Am J Hosp Pharm. 1990;47(3):533-43. 
2. Fink JC, Brown J, Hsu VD, Seliger SL, Walker L, Zhan M. CKD as an underrecognized threat to patient safety. Am J Kidney Dis. 2009;53(4):681-8.

3. Stevens LA, Li S, Wang C, Huang C, Becker BN, Bomback AS, et al. Prevalence of CKD and comorbid illness in elderly patients in the United States: results from the Kidney Early Evaluation Program (KEEP). Am J Kidney Dis. 2010;55(3 Suppl 2):S23-33.

4. US Renal Data System. USRDS 2012 annual data report: atlas of chronic kidney disease and end-stage renal disease in the United States. Bethesda (MD): National Institutes of Health, National Institute of Diabetes and Digestive and Kidney Diseases; 2012.

5. Laliberté MC, Normandeau M, Lord A, Lamarre D, Cantin I, Berbiche D, et al. Use of over-the-counter medications and natural products in patients with moderate and severe chronic renal insufficiency. Am J Kidney Dis. 2007;49(2):245-56.

6. Breton G, Froissart M, Janus N, Launay-Vacher V, Berr C, Tzourio C, et al. Inappropriate drug use and mortality in community-dwelling elderly with impaired kidney function-the Three-City population-based study. Nephrol Dial Transplant. 2011;26(9):2852-9.

7. MedsCheck. Toronto (ON): Ontario Ministry of Health and Long-Term Care; 2008 [cited 2014 Mar 20]. Available from: www.health.gov.on.ca/en/ pro/programs/drugs/medscheck/medscheck_original.aspx

8. Matzke GR, St Peter WL, Comstock TJ, Foote EF. Nephrology pharmaceutical care preceptorship: a programmatic and clinical outcomes assessment. Ann Pharmacother. 2000;34(5):593-9.

9. Cesta A, Bajcar JM, Ong SW, Fernandes OA. The EMITT study: development and evaluation of a medication information transfer tool. Ann Pharmacother. 2006;40(6):1074-81.

10. Munday A, Kelly B, Forrester JWE, Timoney A, McGovern E. Do general practitioners and community pharmacists want information on the reasons for drug therapy changes implemented by secondary care? $\mathrm{Br} J$ Gen Pract. 1997;47(422):563-6.

11. Riley KD, Wazny LD. Assessment of a fax document for transfer of medication information to family physicians and community pharmacists caring for hemodialysis outpatients. CANNT J. 2006;16(1):24-8.

12. Fisher J, Macintyre J, Kinnear M, Hudson S. Design and evaluation of a documentation system to support the continuity of pharmaceutical care of day-case oncology patients between hospital and community pharmacists. Int J Pharm Pract. 2006;14(2):149-57.

13. Bhaloo S, Fox A. Assessment of the educational needs of community pharmacists who provide pharmaceutical care to renal transplant patients [abstract]. Can J Hosp Pharm. 2005;58 Suppl 1:52.
14. Lalonde L, Normandeau M, Lamarre D, Lord A, Berbiche D, Corneille L, et al. Evaluation of a training and communication-network nephrology program for community pharmacists. Pharm World Sci. 2008;30(6):924-33.

15. Scott VG, Amonkar MM, Madhavan SS. Pharmacists' preferences for continuing education and certificate programs. Ann Pharmacother. 2001; 35(3):289-99.

16. Abbott R, Edwards S, Whelan M, Edwards J, Dranitsaris G. Are community pharmacists equipped to ensure safe use of oral anticancer therapy in the community setting? Results of a cross-country survey of community pharmacists in Canada. J Oncol Pharm Pract. 2014;20(1):29-39.

17. Liekens S, Smits T, Laekeman G, Foulon V. Pharmaceutical care for people with depression: Belgian pharmacists' attitudes and perceived barriers. Int $J$ Clin Pharm. 2012;34(3):452-9.

Lisa Zhu, BScPhm, ACPR, PharmD, is a Clinical Pharmacist in the Division of Nephrology, Sunnybrook Health Sciences Centre, Toronto, Ontario.

Andrea Fox, BSC, BSCPhm, is a Clinical Pharmacist in the Division of Nephrology, Sunnybrook Health Sciences Centre, Toronto, Ontario.

Yu Chun Chan, BSc, BScPhm, was, at the time the study was conducted, a pharmacy research student at Sunnybrook Health Sciences Centre, Toronto, Ontario. He is now a Clinical Pharmacist with North York General Hospital, Toronto, Ontario.

Competing interests: None declared.

\section{Address correspondence to:}

Dr Lisa Zhu

Department of Pharmacy

Sunnybrook Health Sciences Centre

2075 Bayview Avenue

Toronto ON M4N 3M5

e-mail: lisa.zhu@sunnybrook.ca

\section{Acknowledgements}

We thank Charles Zhu for his assistance in developing the online version of the survey. 